\title{
Pulmonary Vasodilator Responses to Nitroprusside and Nitroglycerin in the Dog
}

\author{
Philip J. Kadowitz, Premanand Nandiwada, Carl A. Gruetter, \\ Louis J. IgNarro, and AlBert L. Hyman, Departments of Pharmacology \\ and Surgery, Tulane University School of Medicine, New Orleans, \\ Louisiana 70112
}

\begin{abstract}
A B S TRACT. The objective of this study was to determine the direct actions of nitroprusside and nitroglycerin on the pulmonary vascular bed in the intactchest dog. These widely used nitrogen oxide-containing vasodilator agents decreased pulmonary arterial pressure and increased cardiac output without altering left atrial pressure. Reductions in pulmonary arterial pressure and pulmonary vascular resistance were small under resting conditions, but were enhanced when pulmonary vascular tone was elevated by infusion of a stable prostaglandin analog that increases pulmonary vascular resistance by constricting intrapulmonary veins and upstream segments. In studies in which pulmonary blood flow to the left lower lobe was maintained constant, nitroprusside and nitroglycerin caused small but significant reductions in lobar arterial and small-vein pressures without significantly affecting left atrial pressure. With constant blood flow, lobar vascular pressures that were reduced in response to the vasodilators were more greatly reduced when lobar vascular resistance was increased by infusion of the prostaglandin analog or serotonin. However, when lobar vascular pressures were elevated by passive obstruction of lobar venous outflow, vasodilator responses to nitroprusside and nitroglycerin were not enhanced. These data suggest that nitroprusside and nitroglycerin decrease pulmonary vascular resistance by dilating intrapulmonary veins and upstream segments. These responses were minimal under control conditions but were enhanced when vascular tone was increased. This vasodilator action is independent of passive factors such as changes in pulmonary blood flow or left atrial pressure and is not secondary to an effect of these agents on the systemic circulation. Pulmonary vasodilator responses to nitroprusside and nitroglycerin were, however, found to be dependent on the existing level of vasomotor tone in the pulmonary vascular bed.
\end{abstract}

Received for publication 26 May 1980 and in revised form 6 November 1980.

\section{INTRODUCTION}

The major pharmacologic property of drugs belonging to the class of organic nitrates and other nitrogen oxide-containing agents such as nitroprusside is to relax vascular smooth muscle (1). Nitroglycerin is a vasodilator agent that is widely used in the treatment of anginal disease whereas nitroprusside is used in the management of hypertensive emergencies and for afterload reduction in patients with left heart failure and myocardial infarction (1-4). Although the systemic vascular responses to nitroprusside and nitroglycerin have been intensively investigated (5-8), the actions of these substances on the pulmonary circulation have received less attention and little, if anything, is known about the effects of these agents on the pulmonary veins (9-13). Nitroprusside and nitroglycerin have been reported to decrease pulmonary arterial pressure in patients with congestive heart failure (9-12). However, in those studies the vasodilator agents increased cardiac output and, when measured, decreased pulmonary arterial-wedge pressure so that the direct effects of these substances on the pulmonary vascular bed are uncertain (9-12). In a recently published study nitroprusside was reported to have no significant effect on pulmonary arterial pressure in the dog and the authors speculate that this vasodilator agent reduces pulmonary vascular distending pressure through its actions on the systemic circulation (13). It was also reported in that study that nitroprusside altered the pressure-volume characteristics of the pulmonary circulation (13). The present study was undertaken to investigate the direct actions of nitroprusside and nitroglycerin on the pulmonary vascular bed under base-line conditions, when pulmonary vascular resistance was increased actively and when pulmonary vascular pressures were increased passively by obstructing pulmonary lobar-venous outflow. The present studies indicate that nitroprusside and nitroglycerin dilate the pulmonary vascular bed by a direct action on pulmonary veins and upstream segments and sug- 
gest that vasodilator responses to these agents are dependent on the existing level of tone in the pulmonary vessels.

\section{METHODS}

Cardiopulmonary responses to nitroprusside and nitroglycerin were investigated in 35 mongrel dogs of either sex weighing $15-22 \mathrm{~kg}$. The animals were anesthetized with pentobarbital sodium, $30 \mathrm{mg} / \mathrm{kg}$ i.v., and were strapped in the supine position to a Philips fluoroscopic table (Philips Electronic Instruments, Inc., Mahwah, N. J.). Supplemental doses of anesthetic were administered as needed to maintain a uniform level of anesthesia and the animals spontaneously breathed room air enriched with $100 \% \mathrm{O}_{2}$ through a cuffed endotracheal tube. The $\mathrm{FIO}_{2}$ was not measured; however, the $\mathrm{O}_{2}$ flow in the endotracheal catheter was kept constant during an experiment. In the 16 animals in which responses were investigated when cardiac output and pulmonary blood flow varied naturally, pulmonary arterial pressure was measured with a $3 F$ Teflon catheter with end and side holes passed into the main pulmonary artery under fluoroscopic guidance (Philips image intensifier, Philips Electronic Instruments, Inc.) from an external jugular vein. For measurement of left atrial pressure a $6 \mathrm{~F}$ Teflon catheter with end and side holes was passed into the left atrium transseptally from an external jugular vein under fluoroscopic guidance using a Ross transseptal needle (Becton-Dickinson \& Co., Rutherford, N. J.). Systemic arterial pressure was measured from a $7 \mathrm{~F}$ catheter inserted into the aorta from a femoral artery and central venous pressure was measured from a $6 \mathrm{~F}$ catheter positioned at the junction of the superior vena cava and the right atrium. All vascular pressures were measured with Statham P23D transducers (Statham Instruments, Inc., Oxnard, Calif.) zeroed at right atrial level; mean pressures obtained by electronic averaging were recorded on an oscilloscopic recorder, model DR-12 (Electronics for Medicine, Inc., Pleasantville, N. Y.). A $5 \mathrm{~F}$ double lumen thermistor-tip thermodilution catheter and KMA model 3500 computer (Kimray Medical Assoc., Oklahoma City, Okla.) were used to measure cardiac output by the thermodilution technique (14). The thermistor-tip catheter was positioned in the main pulmonary artery and the injectate, $5 \mathrm{ml}$ of $0.9 \% \mathrm{NaCl}$ at room temperature $\left(22-24^{\circ} \mathrm{C}\right)$, was rapidly injected into the proximal port on the thermistor catheter. After all catheters were secured, the animals were heparinized $500 \mathrm{U} / \mathrm{kg}$ i.v., and were permitted to stabilize for $30 \mathrm{~min}$ before experiments were started. Cardiac output during the control period averaged $121 \mathrm{ml} / \mathrm{kg}$ per min and is in agreement with previous studies from this laboratory $(15,16)$.

In the 20 animals in which blood flow to the left lower lobe was maintained constant, a specially designed $20 \mathrm{~F}$ balloon perfusion catheter (U. S. Catheter and Instrument Co., Glen Falls, N. Y.) was positioned in the artery to the left lower lobe from the left external jugular vein under fluoroscopic guidance. A 2-mm Teflon catheter with end and side holes and with its tip positioned $1-2-\mathrm{cm}$ distal to the balloon on the perfusion catheter was used to measure perfusion pressure in the lobar artery. In these experiments, catheters with end and side holes were passed into the aorta and into the left atrium transseptally. For measurement of small intrapulmonary vein pressures a $0.9-\mathrm{mm}$ Teflon catheter with end and side holes near the tip was passed through a 3F Teflon catheter that previously had been wedged in a small intrapulmonary vein and this catheter was also wedged in yet a smaller vein. The $0.9-\mathrm{mm}$ catheter was then withdrawn from the wedge position until pressure dropped from a wedge value which approximated lobar arterial pressure to smallvein pressure $(8-11 \mathrm{~mm} \mathrm{Hg}$ ) and the pressure waveform followed the contour of the pressure waveform in the large vein. The $0.9-\mathrm{mm}$ catheter was fixed in place by means of a Cope adaptor (Becton-Dickinson \& Co.) after the $3 F$ catheter had been withdrawn to the left atrium. The procedure for measurement of small intrapulmonary vein pressures has been described $(17,18)$. After all catheters were positioned and the animals heparinized, 1,000 U/kg i.v., the balloon on the perfusion catheter was gradually distended with 2-4 ml of contrast media (Hypaque, sodium diatrizoate, 50\%, Winthrop Labs, Evanston, Ill.) until lobar arterial and small-vein pressures decreased to near left atrial pressure. The vascularly isolated left lower lobe was then autoperfused with blood withdrawn by way of a $12 \mathrm{~F}$ withdrawal catheter passed into the right atrium from a femoral vein. The lobe was perfused by means of a roller pump (model 3500, Sarns, Inc., Ann Arbor, Mich.) and the pumping rate was adjusted so that mean pressures in the lobar artery and main pulmonary artery were similar. The pumping rate was $293 \pm 12 \mathrm{ml} / \mathrm{min}$ (mean $\pm \mathrm{SE}, n=20$ ) and was not altered during an experiment. In experiments in which lobar vascular pressures were passively increased by obstructing lobar venous outflow, a $12 \mathrm{~F}$ double lumen catheter (U. S. Catheter and Instrument $\mathrm{Co}$.) was passed from an external jugular vein transseptally into the left atrium and positioned in the vein draining the left lower lobe 1-2-cm upstream from the venoatrial junction. Lobar venous outflow was partially obstructed by slowly distending the balloon on the catheter with contrast media. Elevations in lobar arterial and venous pressures were well maintained during the period of balloon distension and pressures rapidly returned to base-line value when the contrast medium was withdrawn from the balloon.

Arterial blood gases and $\mathrm{pH}$ were measured with a model Micro 13 analyzer (Instrumentation Laboratory, Inc., Lexington, Mass.). Blood samples were withdrawn from the aorta in the control period and during peak responses to nitroprusside and nitroglycerin. During the maximum fall in pulmonary arterial pressure in response to injections of nitroprusside $(100$ $\mu$ g i.v.), arterial $\mathrm{PO}_{2}$ fell from $161 \pm 16$ to $148 \pm 8 \mathrm{~mm} \mathrm{Hg}(n=6)$, whereas during infusion of nitroprusside (100 $\mu \mathrm{g} / \mathrm{min}$ i.v.), arterial $\mathrm{Po}_{2}$ fell from $148 \pm 8$ to $130 \pm 5 \mathrm{~mm} \mathrm{Hg}(n=5)$. During the maximum fall in pulmonary arterial pressure in response to nitroglycerin injections (100 $\mu$ g i.v.), arterial $\mathrm{PO}_{2}$ fell from $137 \pm 13$ to $126 \pm 19 \mathrm{~mm} \mathrm{Hg}(n=6)$, whereas during infusion of nitroglycerin ( $100 \mu \mathrm{g} / \mathrm{min}$ i.v.), arterial $\mathrm{Po}_{2}$ fell from $116 \pm 12$ to $114 \pm 4 \mathrm{~mm} \mathrm{Hg}(n=5)$. These values represent mean $\pm \mathrm{SE}$ and the decreases in arterial $\mathrm{PO}_{2}$ were not statistically significant.

Nitroglycerin (Nitrostat, Parke Davis, Ann Arbor, Mich.) and nitroprusside (Nipride, Roche Diagnostics Div., Hoffman-La Roche Inc., Nutley, N. J.) were dissolved in $0.9 \% \mathrm{NaCl}$ and solutions were protected from light in brown stoppered bottles. Solutions were prepared daily and injected intravenously as a rapid bolus in doses of 30,100 , and $300 \mu \mathrm{g}$. All doses were administered in a random order and enough time was permitted between injections for hemodynamic variables to return to base-line levels. Nitroprusside and nitroglycerin were infused intravenously with an infusion pump model 945 (Harvard Apparatus Co., S. Natick, Mass.). Responses to nitroprusside and nitroglycerin were obtained in the control period and when pulmonary vascular resistance was elevated by intravenous infusion of a stable prostaglandin-endoperoxide analog (15S)hydroxyl-1 $1 \alpha, 9 \alpha$ (epoxymethano)prosta5Z,13E dienoic acid (Upjohn Co., Kalamazoo, Mich.). The analog was dissolved in $100 \%$ ethanol at a concentration of 5 $\mathrm{mg} / \mathrm{ml}$ and working solutions were prepared on a weekly basis. The analog was infused with a Harvard pump at rates that increased pulmonary vascular resistance by $\sim 100 \%$ and were 
$0.5-20 \mu \mathrm{g} / \mathrm{min}$. The elevations in pulmonary arterial pressure were well maintained during infusion of the analog and this substance had little, if any, effect on systemic arterial pressure or on cardiac output, and responses to this substance were independent of interaction with formed elements or platelet aggregation (16). In experiments in which responses to nitroprusside and nitroglycerin were investigated in the left lower lobe, these agents were injected directly into the perfused lobar artery in doses of 10-300 $\mu \mathrm{g}$ in a random manner or were infused into the lobar artery at rates of $60-180 \mu \mathrm{g} / \mathrm{min}$. Responses were investigated under baseline conditions and when lobar vascular resistance was elevated by intralobar infusion of the prostaglandin-endoperoxide analog at rates of 0.25-8 $\mu \mathrm{g} / \mathrm{min}$ or elevated by serotonin creatinine sulfate (Sigma Chemical Co., St. Louis, Mo.) at $62-240 \mu \mathrm{g} / \mathrm{min}$.

All hemodynamic data are expressed as mean \pm SE. In experiments in which pulmonary blood flow was not controlled with a pump, cardiac output was measured at the maximum reductions in pulmonary arterial and aortic pressures. Pulmonary vascular resistance expressed in millimeters of mercury per liter per minute was calculated by dividing mean pulmonary arterial pressure minus mean left atrial pressure by the cardiac output. Systemic vascular resistance in the same units was calculated by dividing mean aortic pressure minus mean right atrial pressure by the cardiac output. The data were analyzed by the methods by Snedecor and Cochran (19) for paired or group comparison. A $P$ value of $<0.05$ was used as the criterion for statistical significance.

\section{RESULTS}

Cardiopulmonary responses to nitroprusside and nitroglycerin. Cardiopulmonary responses to nitroprusside and nitroglycerin were investigated in the anesthetized dog under base-line conditions and when pulmonary vascular resistance was elevated by infusion of the stable prostaglandin-endoperoxide analog. Under basal conditions intravenous injections of nitroprusside and nitroglycerin in doses of 100 and 300 $\mu \mathrm{g}$ produced small but statistically significant reductions in mean pulmonary arterial pressure, whereas mean left atrial pressure was unchanged. Cardiac output measured at the maximum fall in pulmonary arterial pressure was increased (Table I). Nitroprusside and nitroglycerin injections also decreased mean systemic arterial pressure without causing any significant effect on mean right atrial pressure (Table II). The fall in systemic arterial pressure preceded the decrease in pulmonary arterial pressure and cardiac output measured at the maximum fall in systemic arterial pressure was increased significantly (Table II). These experiments indicate that under base-line conditions nitroprusside and nitroglycerin decrease pulmonary and systemic vascular resistances in the anesthetized $\operatorname{dog}$ (Tables I and II). Responses to nitroprusside and nitroglycerin were also investigated when pulmonary vascular resistance was increased from an average resting value of $5.2 \pm 0.3$ to $10.3 \pm 0.4 \mathrm{~mm} \mathrm{Hg} /$ liter per min by intravenous infusion of the prostaglandinendoperoxide analog. Reductions in pulmonary arterial pressure and pulmonary vascular resistance in response
TABLE I

Pulmonary Vascular Responses to Intravenous Injections of Sodium Nitroprusside and Nitroglycerin under Base-line Conditions

\begin{tabular}{|c|c|c|c|c|}
\hline & \multicolumn{2}{|c|}{ Pressure } & \multirow[b]{2}{*}{$\begin{array}{l}\text { Cardiac } \\
\text { output }\end{array}$} & \multirow{2}{*}{$\begin{array}{c}\text { Pulmonary } \\
\text { vascular } \\
\text { resistance }\end{array}$} \\
\hline & $\begin{array}{l}\text { Pulmonary } \\
\text { artery }\end{array}$ & $\begin{array}{c}\text { Left } \\
\text { atrium }\end{array}$ & & \\
\hline & \multicolumn{2}{|c|}{$m m H g$} & liter/min & $\underset{\text { liter/min }}{\mathrm{mm} \mathrm{Hg} /}$ \\
\hline Control & $11 \pm 1$ & $3 \pm 0$ & $1.80 \pm 0.14$ & $4.5 \pm 0.4$ \\
\hline $\mathrm{SNP}^{*}(30 \mu \mathrm{g})$ & $10 \pm 2$ & $2 \pm 0$ & $2.14 \pm 0.18 \ddagger$ & $3.6 \pm 0.4$ \\
\hline Control & $12 \pm 1$ & $4 \pm 1$ & $1.67 \pm 0.14$ & $4.5 \pm 0.8$ \\
\hline SNP $(100 \mu \mathrm{g})$ & $9 \pm 1 \ddagger$ & $4 \pm 1$ & $2.26 \pm 0.23 \ddagger$ & $2.5 \pm 0.5 t$ \\
\hline Control & $12 \pm 1$ & $3 \pm 1$ & $1.64 \pm 0.18$ & $5.4 \pm 0.8$ \\
\hline SNP $(300 \mu \mathrm{g})$ & $9 \pm 1 \ddagger$ & $3 \pm 1$ & $2.17 \pm 0.17 \ddagger$ & $2.7 \pm 0.7 \ddagger$ \\
\hline Control & $12 \pm 1$ & $4 \pm 1$ & $1.77 \pm 0.31$ & $4.7 \pm 0.7$ \\
\hline $\mathrm{GTN}^{*}(30 \mu \mathrm{g})$ & $10 \pm 1$ & $2 \pm 1$ & $2.12 \pm 0.38 \ddagger$ & $4.0 \pm 1.2$ \\
\hline Control & $13 \pm 1$ & $2 \pm 1$ & $1.80 \pm 0.32$ & $5.9 \pm 0.7$ \\
\hline GTN $(100 \mu \mathrm{g})$ & $10 \pm 2 \ddagger$ & $2 \pm 1$ & $2.10 \pm 0.40 \ddagger$ & $3.9 \pm 0.8 \ddagger$ \\
\hline Control & $13 \pm 1$ & $2 \pm 1$ & $1.97 \pm 0.28$ & $5.9 \pm 0.7$ \\
\hline GTN $(300 \mu \mathrm{g})$ & $9 \pm 1 \downarrow$ & $1 \pm 1$ & $2.63 \pm 0.49 \ddagger$ & $3.1 \pm 0.8 \neq$ \\
\hline
\end{tabular}

$n=6$.

* SNP, sodium nitroprusside; GTN, nitroglycerin.

$\$ P<0.05$ when compared to corresponding control.

to nitroprusside and to nitroglycerin injections were increased significantly when pulmonary vascular resistance was elevated by infusion of the endoperoxide analog (Figs. 1 and 2).

TABLE II

Systemic Vascular Responses to Intravenous Injections of Sodium Nitroprusside and Nitroglycerin

\begin{tabular}{|c|c|c|c|c|}
\hline & \multicolumn{2}{|c|}{ Pressure } & \multirow[b]{2}{*}{$\begin{array}{l}\text { Cardiac } \\
\text { output }\end{array}$} & \multirow{2}{*}{$\begin{array}{l}\text { Systemic } \\
\text { vascular } \\
\text { resistance }\end{array}$} \\
\hline & Aorta & $\begin{array}{l}\text { Right } \\
\text { atrium }\end{array}$ & & \\
\hline & \multicolumn{2}{|c|}{$m m \mathrm{Hg}$} & liter/min & $\begin{array}{c}m m \mathbf{H g} / \\
\text { liter/min }\end{array}$ \\
\hline Control & $126 \pm 6$ & $2 \pm 1$ & $1.80 \pm 0.14$ & $68.6 \pm 4.9$ \\
\hline SNP $(30 \mu \mathrm{g})$ & $103 \pm 7^{*}$ & $2 \pm 1$ & $2.29 \pm 0.31^{*}$ & $44.0 \pm 6.1^{*}$ \\
\hline Control & $129 \pm 7$ & $2 \pm 1$ & $1.67 \pm 0.14$ & $76.1 \pm 4.5$ \\
\hline SNP $(100 \mu \mathrm{g})$ & $88 \pm 10^{*}$ & $2 \pm 1$ & $2.09 \pm 0.18^{*}$ & $41.1 \pm 4.2^{*}$ \\
\hline Control & $128 \pm 5$ & $2 \pm 1$ & $1.79 \pm 0.18$ & $70.4 \pm 6.3$ \\
\hline SNP $(300 \mu \mathrm{g})$ & $75 \pm 8^{*}$ & $2 \pm 1$ & $2.36 \pm 0.24^{*}$ & $31.0 \pm 2.5^{*}$ \\
\hline Control & $125 \pm 4$ & $1 \pm 1$ & $1.77 \pm 0.36$ & $70.0 \pm 6.8$ \\
\hline GTN $(30 \mu \mathrm{g})$ & $114 \pm 4^{*}$ & $0 \pm 0$ & $1.79 \pm 0.25$ & $63.0 \pm 5.4$ \\
\hline Control & $122 \pm 3$ & $1 \pm 0$ & $1.81 \pm 0.32$ & $67.5 \pm 8.1$ \\
\hline GTN $(100 \mu \mathrm{g})$ & $106 \pm 4^{*}$ & $1 \pm 0$ & $2.62 \pm 0.48^{*}$ & $40.6 \pm 5.8^{*}$ \\
\hline Control & $125 \pm 6$ & $1 \pm 1$ & $1.97 \pm 0.28$ & $63.4 \pm 6.8$ \\
\hline GTN $(300 \mu \mathrm{g})$ & $85 \pm 5^{*}$ & $1 \pm 1$ & $2.74 \pm 0.48^{*}$ & $30.9 \pm 4.9^{*}$ \\
\hline
\end{tabular}

$n=6$. SNP, sodium nitroprusside; GTN, nitroglycerin. ${ }^{*} P<0.05$ when compared to corresponding control. 

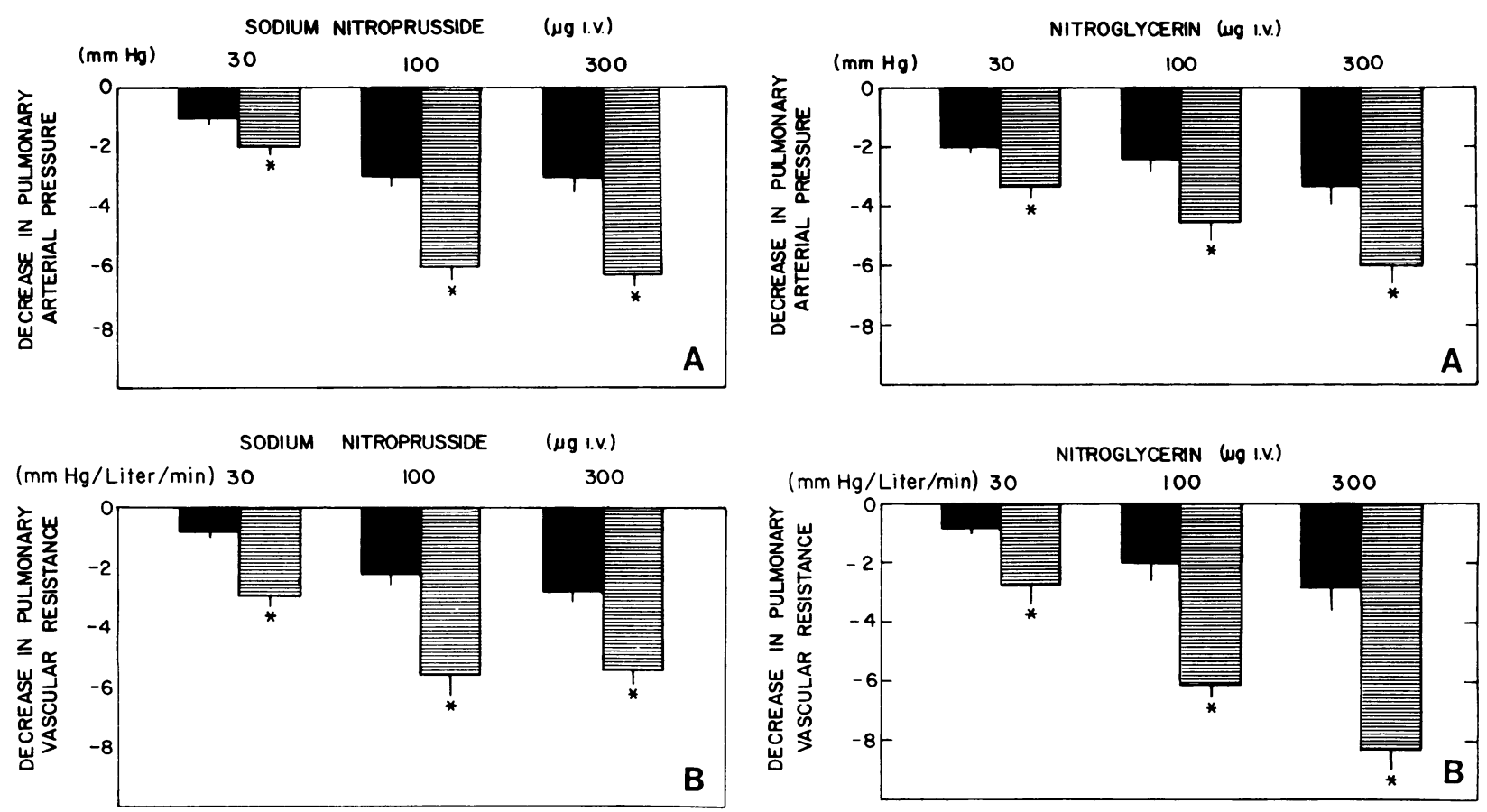

FIGURE 1 Comparison of the effects of i.v. injections of nitroprusside on pulmonary arterial pressure (A) and pulmonary vascular resistance $(B)$ when pulmonary vascular tone was at control levels and when pulmonary vascular tone was elevated by i.v. infusion of the stable prostaglandin-endoperoxide analog. Reductions in pulmonary arterial pressure and pulmonary vascular resistance were significant at the 100 and 300 $\mu \mathrm{g}$ doses of nitroprusside under control conditions. Reductions in pulmonary arterial pressure and pulmonary vascular resistance at all doses were significantly greater than control when tone was elevated $(*, P<0.05)$. $n$ (number of dogs) $=6$ in $\mathrm{A}$ and $\mathrm{B} . \mathbf{\square}$, Control; 自, elevated tone.

Cardiopulmonary responses to intravenous infusions of nitroprusside and nitroglycerin were also investigated in the anesthetized dog and these data are summarized in Tables III and IV. Intravenous infusions of nitroprusside and nitroglycerin, at a rate of $100 \mu \mathrm{g} /$ min decreased mean pulmonary and systemic arterial pressures without changing mean left or right atrial pressures (Table III). Cardiac output increased whereas pulmonary and systemic vascular resistances decreased and all values returned to control level $5 \mathrm{~min}$ after the infusions were discontinued (Table III). The maximum reductions in pulmonary arterial pressure and pulmonary vascular resistance in response to intravenous infusions of nitroprusside and nitroglycerin were significantly greater when pulmonary vascular resistance was elevated by infusion of the prostaglandin analog (Tables III and IV).

Responses to nitroprusside and nitroglycerin in the perfused lobe. Since nitroprusside and nitroglycerin decreased pulmonary arterial pressure and increased pulmonary blood flow, the effects of these substances

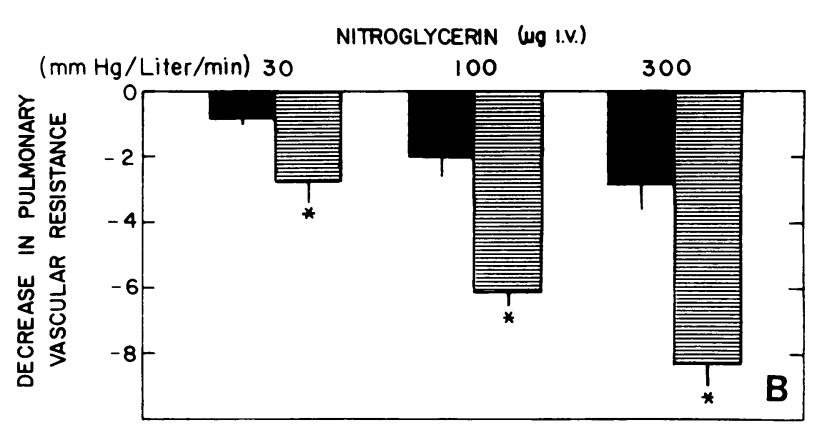

FIGURE 2 Comparative effects of i.v. injections of nitroglycerin on pulmonary arterial pressure (A) and pulmonary vascular resistance (B) when pulmonary vascular tone was at control levels and when pulmonary vascular tone was elevated by i.v. infusion of the stable prostaglandin analog. Decreases in pulmonary arterial pressure and pulmonary vascular resistance were significant at the two higher doses of nitroglycerin under resting conditions. Reductions in pulmonary arterial pressure and pulmonary vascular resistance at all doses were significantly greater than control when tone was elevated $(*, P$ $<0.05$ ), $n$ (number of dogs) $=6$ in A and B. $\mathbf{0}$, Control; E, elevated tone.

were also investigated in another series of experiments in the animal in which blood flow to the left lower lobe was maintained constant with a pump. In addition, to investigate the site of action of these vasodilator agents in the pulmonary vascular bed, pressures were measured in small intrapulmonary veins 2-3- $\mathrm{mm}$ in diameter. In these experiments, injections of nitroprusside in doses of 30-300 $\mu \mathrm{g}$ and nitroglycerin in doses of $10-100 \mu \mathrm{g}$ directly into the lobar artery produced small but statistically significant reductions in mean lobar arterial and small-vein pressures under base-line conditions (Figs. 3 and 4, upper panels). Mean left atrial pressure was unchanged and inasmuch as responses to these agents were not doserelated when lobar vascular resistance was at basal levels, all values were averaged (Figs. 3 and 4, upper panels). However, when lobar vascular resistance was increased from an average base-line value of $0.041 \pm 0.01$ to $0.110 \pm 0.02 \mathrm{~mm} \mathrm{Hg} / \mathrm{ml}$ per min by intrapulmonary infusion of the prostaglandin analog, intralobar injections of $30-300 \mu \mathrm{g}$ nitroprusside 
TABLE III

Hemodynamic Responses to Intravenous Infusions of Sodium Nitroprusside and Nitroglycerin under Base-line Conditions

\begin{tabular}{|c|c|c|c|c|c|}
\hline & \multicolumn{3}{|c|}{ Pressure } & \multirow[b]{2}{*}{ Cardiac output } & \multirow[b]{2}{*}{$\begin{array}{l}\text { Pulmonary vascular } \\
\text { resistance }\end{array}$} \\
\hline & $\begin{array}{c}\text { Pulmonary } \\
\text { artery }\end{array}$ & $\begin{array}{c}\text { Left } \\
\text { atrium }\end{array}$ & Aorta & & \\
\hline & \multicolumn{3}{|c|}{$m m \mathrm{Hg}$} & liter/min & $\mathrm{mm} \mathrm{Hg} /$ liter/min \\
\hline Control & $12 \pm 2$ & $3 \pm 1$ & $116 \pm 9$ & $1.49 \pm 0.21$ & $6.04 \pm 1.2$ \\
\hline \multicolumn{6}{|l|}{ SNP infusion } \\
\hline $1 \mathrm{~min}$ & $10 \pm 2$ & $3 \pm 2$ & $109 \pm 11$ & $1.60 \pm 0.32$ & $4.37 \pm 0.9$ \\
\hline $2 \min$ & $9 \pm 1^{*}$ & $2 \pm 0$ & $91 \pm 6^{*}$ & $1.97 \pm 0.38^{*}$ & $3.55 \pm 1.0^{*}$ \\
\hline $4 \mathrm{~min}$ & $8 \pm 1^{*}$ & $2 \pm 1$ & $98 \pm 8^{*}$ & $1.90 \pm 0.28^{*}$ & $3.33 \pm 0.6^{*}$ \\
\hline $6 \mathrm{~min}$ & $8 \pm 2^{*}$ & $2 \pm 1$ & $97 \pm 7^{*}$ & $1.82 \pm 0.21^{*}$ & $3.29 \pm 0.6^{*}$ \\
\hline After infusion & $13 \pm 3$ & $2 \pm 0$ & $114 \pm 8$ & $1.39 \pm 0.41$ & $7.91 \pm 1.1$ \\
\hline Control & $13 \pm 2$ & $3 \pm 0$ & $121 \pm 7$ & $1.54 \pm 0.17$ & $6.5 \pm 1.5$ \\
\hline \multicolumn{6}{|l|}{ GTN infusion } \\
\hline $1 \mathrm{~min}$ & $11 \pm 2$ & $3 \pm 0$ & $120 \pm 7$ & $1.60 \pm 0.19$ & $5.0 \pm 1.3$ \\
\hline $2 \mathrm{~min}$ & $7 \pm 2^{*}$ & $2 \pm 0$ & $112 \pm 9^{*}$ & $1.60 \pm 0.21$ & $3.2 \pm 1.2^{*}$ \\
\hline $4 \mathrm{~min}$ & $8 \pm 2^{*}$ & $2 \pm 0$ & $108 \pm 8^{*}$ & $1.82 \pm 0.17^{*}$ & $3.2 \pm 0.8^{*}$ \\
\hline $6 \mathrm{~min}$ & $7 \pm 2^{*}$ & $2 \pm 0$ & $109 \pm 7^{*}$ & $1.73 \pm 0.52$ & $2.8 \pm 0.8^{*}$ \\
\hline After infusion & $12 \pm 2$ & $2 \pm 0$ & $119 \pm 8$ & $1.62 \pm 0.16$ & $6.3 \pm 1.1$ \\
\hline
\end{tabular}

$n=5$. SNP, sodium nitroprusside; GTN, nitroglycerin.

${ }^{*} P<0.05$ when compared to corresponding control.

and 10-100 $\mu$ g nitroglycerin caused dose-dependent decreases in lobar arterial and small-vein pressures that were significantly greater than were the responses observed under basal conditions (Figs. 3 and 4 ). Meanwhile, lobar arterial pressure increased from 16 \pm 1 to $34 \pm 1 \mathrm{~mm} \mathrm{Hg}$ while small-vein pressure in-

TABLE IV

Hemodynamic Responses to Intravenous Infusions of Sodium Nitroprusside and Nitroglycerin when Pulmonary Vascular Resistance was Elevated by Infusion of the Prostaglandin-Endoperoxide Analog

\begin{tabular}{lccccc}
\hline & \multicolumn{3}{c}{ Pressure } & & \\
\cline { 2 - 5 } & $\begin{array}{c}\text { Pulmonary } \\
\text { artery }\end{array}$ & $\begin{array}{c}\text { Left } \\
\text { atrium }\end{array}$ & Aorta & Cardiac output & $\begin{array}{c}\text { Pulmonary vascular } \\
\text { resistance }\end{array}$ \\
\hline & & $m m ~ H g$ & & liter/min & mm Hg/liter/min \\
Control & $24 \pm 3$ & $3 \pm 1$ & $119 \pm 4$ & $1.64 \pm 0.31$ & $12.80 \pm 2.0$ \\
SNP infusion & & & & & \\
1 min & $20 \pm 2^{*}$ & $2 \pm 1$ & $110 \pm 5$ & $1.83 \pm 0.25^{*}$ & $9.94 \pm 1.1^{*}$ \\
2 min & $18 \pm 2^{*}$ & $2 \pm 0$ & $101 \pm 8^{*}$ & $1.80 \pm 0.32^{*}$ & $8.88 \pm 0.9^{*}$ \\
4 min & $14 \pm 2^{*}$ & $1 \pm 0$ & $100 \pm 6^{*}$ & $1.86 \pm 0.27^{*}$ & $7.18 \pm 1.0^{*}$ \\
6 min & $15 \pm 2^{*}$ & $1 \pm 1$ & $102 \pm 4^{*}$ & $1.70 \pm 0.36$ & $8.23 \pm 0.8$ \\
After infusion & $22 \pm 3$ & $2 \pm 0$ & $118 \pm 6$ & $1.58 \pm 0.38$ & $12.65 \pm 1.8$ \\
Control & $24 \pm 2$ & $5 \pm 1$ & $135 \pm 10$ & $1.60 \pm 0.26$ & $11.80 \pm 2.6$ \\
GTN infusion & & & & & $1.94 \pm 0.28^{*}$ \\
$\quad 1$ min & $18 \pm 2^{*}$ & $3 \pm 1$ & $126 \pm 9$ & $1.80 \pm 0.26^{*}$ & $7.70 \pm 1.2^{*}$ \\
2 min & $16 \pm 2^{*}$ & $3 \pm 1$ & $120 \pm 8^{*}$ & $1.20 \pm 1.8^{*}$ \\
4 min & $13 \pm 1^{*}$ & $3 \pm 0$ & $118 \pm 8^{*}$ & $1.92 \pm 0.31^{*}$ & $5.20 \pm 1.1^{*}$ \\
6 min & $12 \pm 1^{*}$ & $3 \pm 1$ & $115 \pm 7^{*}$ & $1.80 \pm 0.27^{*}$ & $5.0 \pm 0.9^{*}$ \\
After infusion & $23 \pm 1$ & $4 \pm 1$ & $134 \pm 12$ & $1.58 \pm 0.26$ & $12.0 \pm 2.2$ \\
\hline
\end{tabular}

$n=5$. SNP, sodium nitroprusside; GTN, nitroglycerin.

${ }^{*} P<0.05$ when compared to corresponding control. 


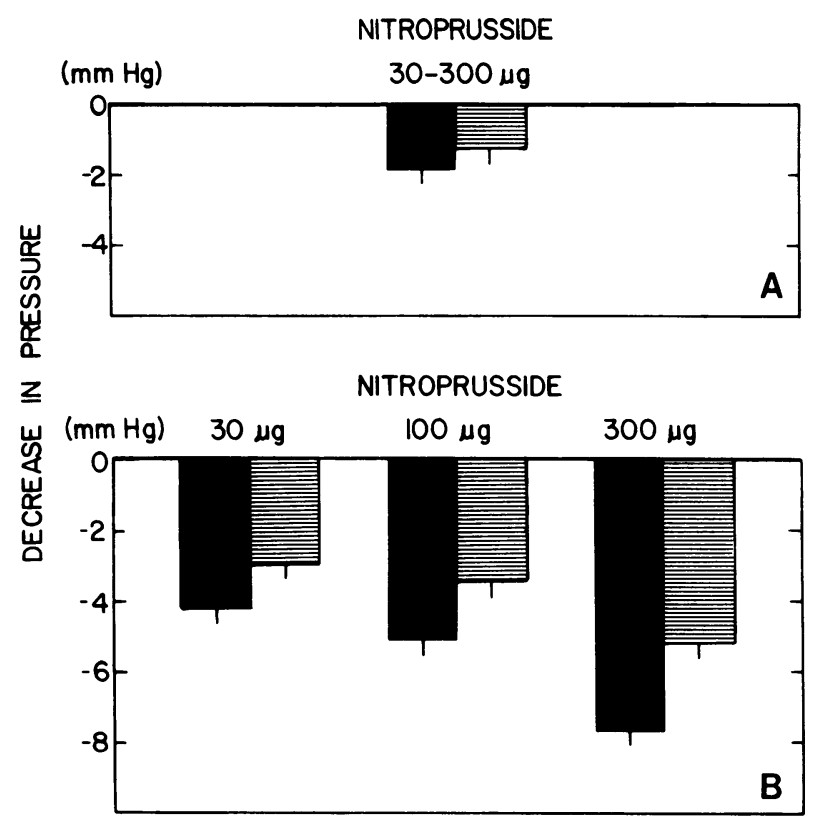

FIGURE 3 Comparison of reductions in lobar arterial $(\boldsymbol{\square})$ and small-vein (国) pressures in response to intralobar injections of nitroprusside, 30-300 $\mu \mathrm{g}$ in the control period (A) and when lobar vascular tone was elevated by intralobar infusion of the prostaglandin-endoperoxide analog (B). The reductions in lobar arterial and venous pressures in response to nitroprusside 30-300 $\mu \mathrm{g}$ were significant during the control period. Reductions in lobar arterial and small-vein pressures were significantly greater at doses of 30,100 , and $300 \mu \mathrm{g}$ when tone was enhanced than the pooled values at $30-300 \mu \mathrm{g}$ during the control period. $n$ (number of animals) $=11$.

creased from $11 \pm 1$ to $22 \pm 1 \mathrm{~mm} \mathrm{Hg}$, whereas left atrial pressure was unchanged.

Lobar vascular responses to nitroprusside and nitroglycerin infusions were also investigated in the perfused lobe. Intralobar infusions of nitroprusside or nitroglycerin $60-180 \mu \mathrm{g} / \mathrm{min}$ for $5 \mathrm{~min}$ caused significant reductions in lobar arterial and small-vein pressures without changing left atrial pressure when lobar vascular tone was elevated by infusion of the endoperoxide analog (Table V). Lobar arterial and smallvein pressures returned to control values after infusions of the vasodilator agents and the prostaglandin analog were discontinued (Table V).

In another series of experiments in which blood flow to lobe was maintained constant, responses to nitroprusside and nitroglycerin were compared when lobar vascular resistance was at basal levels and when tone was increased by intralobar infusion of serotonin. Injections of the vasodilator agents into the lobar artery caused small reductions in lobar arterial pressure under base-line conditions which were significant at the 300 $\mu \mathrm{g}$ dose for nitroprusside and the 30 and $100 \mu \mathrm{g}$ doses for nitroglycerin (Table VI). Intralobar infusion of serotonin $60-240 \mu \mathrm{g} / \mathrm{min}$ increased lobar arterial pressure

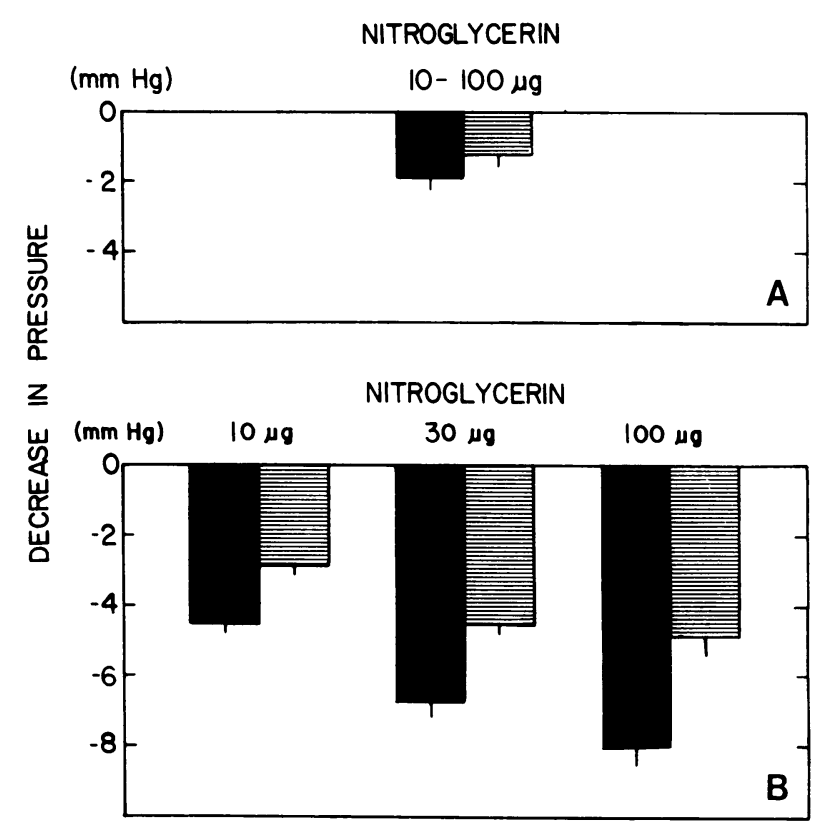

Figure 4 Comparative reductions in lobar arterial and small vein-pressures in response to intralobar injections of 10-100 $\mu \mathrm{g}$ nitroglycerin in the control period (A) and when lobar vascular tone was elevated by intralobar infusion of the prostaglandin-endoperoxide analog (B). Decreases in lobar arterial and venous pressures in response to $10-100 \mu \mathrm{g}$ nitroglycerin were significant during the control period. Decreases in lobar arterial and small-vein pressures were significantly greater at doses of 10,30 , and $100 \mu \mathrm{g}$ when tone was elevated than the pooled values at $10-100 \mu$ g during the control period. $n$ (num-

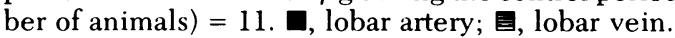

without altering left atrial pressure (Table VI). When lobar vascular resistance was increased by infusion of serotonin, reductions in lobar arterial pressure in response to intralobar injections of nitroprusside and nitroglycerin were greatly enhanced (Table VI).

Lobar responses to nitroprusside and nitroglycerin when lobar vascular pressures were increased passively. Lobar vascular responses to nitroprusside and nitroglycerin were also investigated when lobar arterial and small-vein pressures were elevated by partial obstruction of lobar venous outflow by means of a balloon catheter in the vein draining the left lower lobe. Under base-line conditions there was no significant pressure gradient across the balloon in the lobar vein and intralobar injections of $300 \mu \mathrm{g}$ nitroprusside and $100 \mu \mathrm{g}$ nitroglycerin caused small statistically significant reductions in lobar arterial and small-vein pressures (Fig. 5, upper panel). The balloon was then slowly distended with contrast medium until mean pressures in the lobar artery and small vein were elevated to approximately the same levels as observed during intrapulmonary infusion of the prostaglandin analog (Table VII). Balloon distension increased mean lobar arterial and small vein pressures without affecting mean left 
TABLE V

Influence of Intra-lobar Infusions of Sodium Nitroprusside and Nitroglycerin when Lobar Vascular Pressures were Elevated by Infusion of the Endoperoxide Analog

\begin{tabular}{llcc}
\hline & \multicolumn{3}{c}{ Pressure } \\
\cline { 2 - 4 } & $\begin{array}{c}\text { Lobar } \\
\text { artery }\end{array}$ & $\begin{array}{c}\text { Small } \\
\text { vein }\end{array}$ & $\begin{array}{c}\text { Left } \\
\text { atrium }\end{array}$ \\
\hline & & $m m H g$ \\
Control & $14 \pm 2$ & $9 \pm 2$ & $3 \pm 1$ \\
Endoperoxide* infusion & $31 \pm 3 \ddagger$ & $19 \pm 2 \ddagger$ & $3 \pm 1$ \\
SNP infusion $\oint$ & $23 \pm 2 \ddagger$ & $14 \pm 2 \ddagger$ & $3 \pm 1$ \\
After SNP and analog infusion & $16 \pm 2$ & $11 \pm 3$ & $3 \pm 1$ \\
Control & $15 \pm 2$ & $9 \pm 1$ & $4 \pm 1$ \\
Endoperoxide* infusion & $33 \pm 2 \ddagger$ & $23 \pm 2 \ddagger$ & $4 \pm 1$ \\
GTN infusion $\oint$ & $24 \pm 2 \ddagger$ & $16 \pm 4 \ddagger$ & $4 \pm 1$ \\
After GTN and analog infusion & $15 \pm 1$ & $8 \pm 2$ & $4 \pm 1$ \\
& & &
\end{tabular}

$n=4$. SNP, sodium nitroprusside; GTN, nitroglycerin.

* Infused into the lobar artery at $1-8 \mu \mathrm{g} / \mathrm{min}$.

$\ddagger P<0.05$ when compared to control, paired comparison.

$\$$ Infused into the lobar artery at $60-180 \mu \mathrm{g} / \mathrm{min}$ for a period of $5 \mathrm{~min}$.

atrial or aortic pressure (Table VII). The elevations in lobar arterial and venous pressures were well maintained during the period of balloon distension and the lobar arterial to small-vein pressure gradient decreased

TABLE VI

Lobar Vascular Responses to Sodium Nitroprusside and Nitroglycerin under Base-line Conditions and during Infusion of Serotonin

\begin{tabular}{llllll}
\hline & \multicolumn{2}{c}{ Base-line } & & \multicolumn{2}{c}{$\begin{array}{c}\text { During 5-HT } \\
\text { infusion }\end{array}$} \\
\cline { 2 - 3 } \cline { 5 - 6 } & $\begin{array}{l}\text { Lobar } \\
\text { artery }\end{array}$ & $\begin{array}{c}\text { left } \\
\text { atrium }\end{array}$ & & $\begin{array}{c}\text { Lobar } \\
\text { artery }\end{array}$ & $\begin{array}{c}\text { Left } \\
\text { atrium }\end{array}$ \\
& & & $m m ~ H g$ & & \\
Control & $11 \pm 1$ & $1 \pm 1$ & $24 \pm 3$ & $1 \pm 1$ \\
SNP $(30 \mu \mathrm{g})$ & $11 \pm 1$ & $1 \pm 1$ & $20 \pm 3 \ddagger$ & $1 \pm 1$ \\
Control & $12 \pm 1$ & $1 \pm 1$ & $28 \pm 4$ & $1 \pm 1$ \\
SNP $(100 \mu \mathrm{g})$ & $11 \pm 1$ & $0 \pm 0$ & $22 \pm 3 \ddagger$ & $1 \pm 0$ \\
Control & $12 \pm 1$ & $0 \pm 0$ & $28 \pm 3$ & $1 \pm 1$ \\
SNP $(300 \mu \mathrm{g})$ & $10 \pm 1 \ddagger$ & $0 \pm 0$ & $21 \pm 3 \ddagger$ & $1 \pm 1$ \\
Control & $11 \pm 0$ & $1 \pm 1$ & $24 \pm 3$ & $1 \pm 1$ \\
GTN $(10 \mu \mathrm{g})$ & $10 \pm 0$ & $1 \pm 1$ & $21 \pm 2 \ddagger$ & $1 \pm 0$ \\
Control & $12 \pm 1$ & $1 \pm 1$ & $27 \pm 4$ & $1 \pm 0$ \\
GTN $(30 \mu \mathrm{g})$ & $10 \pm 1 \ddagger$ & $1 \pm 0$ & $22 \pm 3$ & $1 \pm 1$ \\
Control & $12 \pm 1$ & $1 \pm 1$ & $28 \pm 4$ & $1 \pm 1$ \\
GTN $(100 \mu \mathrm{g})$ & $10 \pm 1 \ddagger$ & $1 \pm 1$ & $20 \pm 3 \ddagger$ & $1 \pm 1$ \\
\hline
\end{tabular}

$n=5$. SNP, sodium nitroprusside; GTN, nitroglycerin.

* 5-HT, serotonin, infused into the lobar artery at 60-240 $\mu \mathrm{g} / \mathrm{min}$.

$\ddagger P<0.05$. when compared to corresponding control, paired comparison.

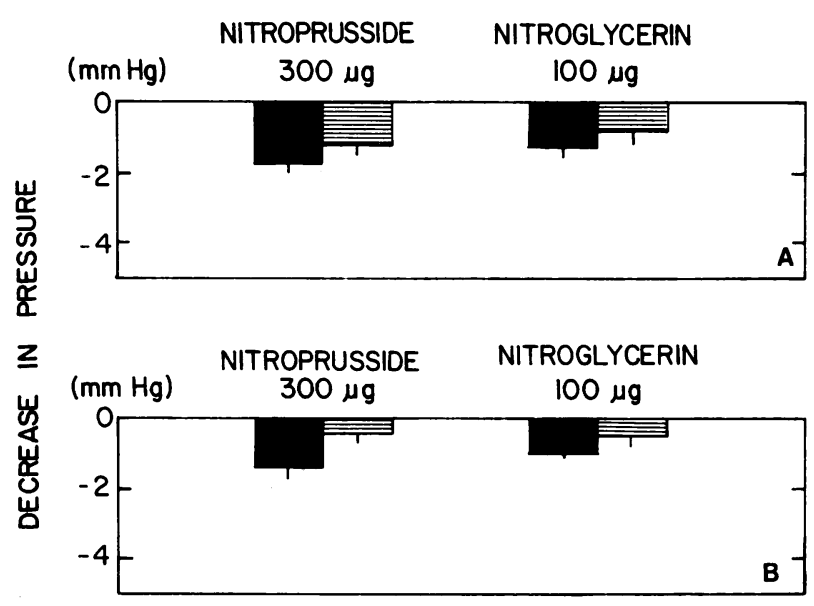

Figure 5 Comparative decreases in lobar arterial and small vein pressures in the control period (A) and when lobar vascular pressures were elevated passively by distension of a balloon in the vein draining the left lower lobe (B). Reductions in lobar arterial and venous pressures in response to nitroprusside and nitroglycerin were significant during the control period whereas only decreases in lobar arterial pressure in response to the organic nitrates were significant when lobar venous outflow was partially obstructed. $n$ (number of animals) $=4$. $\square$, lobar artery; 冒, lobar vein.

significantly, whereas the small vein to left atrial pressure gradient increased significantly (Table VII). Although lobar arterial and small-vein pressures were increased by obstructing lobar venous outflow, lobar vascular responses to nitroprusside and nitroglycerin were not enhanced when lobar vascular pressures were elevated passively (Fig. 5).

\section{DISCUSSION}

Results of the present study in the dog show that nitroprusside and nitroglycerin decrease pulmonary and systemic arterial pressures. The reduction in pulmo-

TABLE VII

Lobar Vascular Responses to Partial Obstruction Of Lobar Venous Outflow

\begin{tabular}{lrc}
\hline & \multicolumn{2}{c}{ Control balloon distended } \\
\hline & \multicolumn{2}{c}{$m m \mathrm{Hg}$} \\
Pressure & $17 \pm 1$ & $35 \pm 3^{*}$ \\
Lobar artery & $10 \pm 1$ & $30 \pm 3^{*}$ \\
Small vein & $2 \pm 0$ & $2 \pm 0$ \\
Left atrium & $103 \pm 6$ & $99 \pm 4$ \\
Aorta & & \\
Gradient & $7 \pm 1$ & $5 \pm 2^{*}$ \\
Lobar artery - small vein & $8 \pm 2$ & $20 \pm 4^{*}$ \\
Small vein-left atrium & & \\
\hline
\end{tabular}

$n=4$.

${ }^{*} P<0.05$, significantly different from corresponding control. 
nary arterial pressure was greatly enhanced when pulmonary vascular tone was increased by infusion of a stable prostaglandin analog. Inasmuch as cardiac output increased and left and right atrial pressures were not changed, the reductions in pulmonary and systemic arterial pressures indicate that pulmonary and systemic vascular resistances decreased. However, an increase in cardiac output or pulmonary blood flow will passively decrease pulmonary vascular resistance $(17,20)$. Therefore, the direct effects of nitroprusside and nitroglycerin and the site of action in the pulmonary vascular bed were investigated in experiments in which blood flow was controlled with a pump and pressure gradients across the lobe were measured in the intact-chest animal. Results of these experiments indicate that nitroprusside and nitroglycerin produce small reductions in lobar arterial and venous pressures and that reductions in lobar vascular pressures were greatly enhanced when vasoconstrictor tone in the lobe was increased by infusion of the stable prostaglandin analog, which constricts intrapulmonary veins and upstream segments. Because blood flow was constant in these experiments and left atrial pressure did not change significantly, the data suggest that the nitrogen oxide-containing agents decrease vascular resistance in the lung by dilating intrapulmonary veins and upstream segments. The observation that vasodilator responses to nitroglycerin and nitroprusside were small under base-line conditions but were greatly enhanced when vasoconstrictor tone in the lobe was elevated by the prostaglandin analog or serotonin suggests that under basal conditions, vasoconstrictor tone in the pulmonary vascular bed is minimal. In addition, these data suggest that vasodilator responses to the nitrogen oxide-containing agents are dependent on the existing level of vasomotor tone in the pulmonary vascular bed.

Although vasodilator responses to nitroprusside and nitroglycerin were enhanced when pulmonary vasomotor tone was increased by an active process, responses to these agents were not enhanced when lobar vascular pressures were passively elevated by partially obstructing lobar venous outflow. These data suggest that reductions in pulmonary arterial pressure in response to nitroprusside in patients with congestive heart failure may, for the most part, be passive in nature and may be secondary to the improvement in left ventricular function which results in reductions in left ventricular end-diastolic and left atrial pressures (4, 9-12). The passive nature of the pulmonary response to nitroprusside was observed in a recently published study in which this agent produced similar decreases in mean pulmonary arterial $(11.7 \pm 1.5 \mathrm{~mm} \mathrm{Hg})$ and mean pulmonary arterial-wedge pressures $(11.0 \pm 1.5$ $\mathrm{mm} \mathrm{Hg}$ ) in patients with congestive heart failure (12). The present data with passive increases in pulmonary vascular pressures are also consistent with a recently published study in the dog in which nitroprusside had little if any effect on pulmonary arterial pressure when intravascular volume was expanded by infusion of 2-3 Liters of saline or when autologous blood was transfused (13). However, the present study extends the results of previous studies by showing that nitroprusside and nitroglycerin have marked vasodilator activity in the pulmonary vascular bed when pulmonary vascular resistance is increased by an active process. In addition, our study shows that vasodilator responses to these agents are not related to changes in pulmonary blood flow or left atrial pressure since responses could be demonstrated in experiments in which blood flow was constant and left atrial pressure did not change.

In experiments in which pulmonary blood flow was not controlled, the decrease in pulmonary arterial pressure followed the fall in systemic arterial pressure indicating that pulmonary vascular responses to nitroprusside and nitroglycerin may be secondary to changes in the systemic circulation, as was recently suggested (13). However, the present experiments in the perfused lobe indicate that responses to nitroprusside or nitroglycerin were not secondary to their actions on the systemic circulation, because marked vasodilator responses could be elicited under enhanced tone conditions when these agents were injected directly through the artery to the lobe at lower doses that had no significant effect on left atrial or systemic arterial pressure. Moreover, when injected into the perfused lobar artery in larger doses that decreased systemic arterial pressure, lobar vasodilator response preceded the fall in systemic arterial pressure. These data suggest that nitroprusside and nitroglycerin dilate the pulmonary vascular bed by a direct action on pulmonary vascular smooth muscle. Although the mechanism by which vasodilator agents, like nitroprusside or nitroglycerin, relax vascular smooth muscle is uncertain, earlier studies have suggested that critical sulfhydryl groups may be required for the vasodilator effects of nitrites $(21,22)$. Recent studies in our laboratory have demonstrated that nitroprusside, nitroglycerin, sodium nitrite, and nitric oxide relax coronary arterial smooth muscle and activate soluble guanylate cyclase from the same tissue $(23,24)$. This activation may be due to release of a reactive nitrogen oxide group which results in the elevation of cyclic GMP levels that correlate closely with the smooth muscle relaxation (25). In support of a mechanism involving cyclic GMP, lipophilic analogs of this nucleotide have been shown to relax vascular smooth muscle (26). Preliminary studies from this laboratory indicate that nitroprusside and nitroglycerin activate guanylate cyclase from intrapulmonary vessels. ${ }^{1}$ It is, therefore, possible that these substances

\footnotetext{
${ }^{1}$ McNamara et al. Unpublished results.
} 
dilate pulmonary vessels by elevating cyclic GMP levels in smooth muscle in these vessels.

There has been increased clinical interest in the use of vasodilator agents in the management of cor pulmonale and pulmonary hypertension (27-29). It has been reported that diverse agents such as hydralazine, isoproterenol, diazoxide, tolazoline, and phentolamine may be useful in the treatment of pulmonary hypertension (27-31). It has also been shown that prostacyclin and several prostacyclin-like substances have good vasodilator activity in the pulmonary vascular bed (15, $32-34)$ and it has recently been reported that prostacyclin produced a marked reduction in pulmonary arterial pressure in a patient with severe idiopathic pulmonary hypertension (35). The use of nitroglycerin in the treatment of angina, and nitroprusside in the treatment of hypertensive emergencies and congestive heart failure, is well established (1-4). The present studies suggest that nitroprusside and nitroglycerin are also capable of reducing pulmonary arterial pressure when pulmonary vascular resistance is increased by an active process. In addition, the present data indicate that the nitrogen oxide-containing agents are capable of reducing small-vein pressures. These data suggest that nitroprusside or nitroglycerin may decrease capillary pressure in the lung when pressures in the small veins are increased by an active process. Although the nitrogen oxide-containing agents are capable of reducing afterload on the right side, they also are capable of dilating vessels in poorly ventilated areas of the lung, which may result in a secondary hypoxemia. Therefore, these agents must be used with caution in the management of diseases such as idiopathic pulmonary hypertension, cor pulmonale, and right heart failure where afterload reduction on the right side may be desirable.

\section{ACKNOWLEDGMENTS}

The authors wish to thank Ms. Janice Ignarro and Gilda Duffy for their help in preparing this manuscript. This research was supported by National Institutes of Health grants HL 11802, HL 15580, and AM 17692.

\section{REFERENCES}

1. Goodman, A. G., L. S. Goodman, and A. Gilman. 1980. The Pharmacologic Basis of Therapeutics, 6th Edition. Macmillan Publishing Co., Inc., New York. 819-833.

2. Goldstein, R. E., and S. E. Epstein. 1973. Nitrates in the prophylactic treatment of angina pectoris. Circulation. 48: 917-920.

3. Palmer, R. F., and K. C. Lasseter. 1975. Sodium nitroprusside. N. Engl. J. Med. 292: 294-297.

4. Guiha, N. H., J. N. Cohn, E. Mikulic, J. A. Franciosa, and C. J. Limas. 1974. Treatment of refractory heart failure with infusion of nitroprusside. N. Engl. J. Med. 291: 587591.

5. Vatner, S. F., M. Pogani, J. D. Rutherford, R. W. Millard, and W. T. Manders. 1978. Effects of nitroglycerin on cardiac function and regional blood flow distribution in conscious dogs. Am. J. Physiol. 234: H244-H252.

6. Pagani, M., S. F. Vatner, and E. Braunwald. 1978. Hemodynamic effects of intravenous sodium nitroprusside in the conscious dog. Circulation. 57: 144-151.

7. Rubin, S. A., G. Misbach, J. Lekven, W. A. Parmley, and J. V. Tyberg. 1979. Resistance and volume changes caused by nitroprusside in the dog. Am. J. Physiol. 237: H99H103.

8. Greenway, C. V. 1979. Effects of sodium nitroprusside, isosorbide dinitrate, isoproterenol, phentolamine and prazosin on hepatic venous responses to sympathetic nerve stimulation in the cat. J. Pharmacol. Exp. Ther. 209: 46-61.

9. Mookherjee, S., J. F. H. Keighley, R. A. Warner, M. A. Browser, and A. I. Obeid. 1977. Hemodynamic, ventilatory and blood gas changes during infusion of sodium nitroferricyanide (nitroprusside). Chest. 72: 273-277.

10. Mikulic, E., J. A. Franciosa, and J. N. Cohn. 1975. Comparative hemodynamic effects of chewable isosorbide dinitrate and nitroglycerin in patients with congestive heart failure. Circulation. 52: 477-481.

11. Mookherjee, S., D. Fuleihan, R. A. Warner, S. Vardan, and A. I. Obeid. 1978. Effects of sublingual nitroglycerin on resting pulmonary gas exchange and hemodynamics in man. Circulation. 57: 106-110.

12. Pierpont, G., K. A. Hale, J. A. Franciosa, and J. N. Cohn. 1980. Effects of vasodilators on pulmonary gas exchange in left ventricular failure. Am. Heart J. 99: 208-216.

13. Sivak, E. D., B. A. Gray, H. T. McCurdy, and A. K. Phillips. 1979. Pulmonary vascular response to nitroprusside in dogs. Circ. Res. 45: 360-365.

14. Forrester, J. S., W. Ganz, G. Diamond, T. McHugh, D. W. Chonette, and H. J. C. Swain. 1972. Thermodilution cardiac output determination with a single flow-directed catheter. Am. Heart J. 83: 306-311.

15. Kadowitz, P. J., B. M. Chapnick, L. P. Feigen, A. L. Hyman, P. K. Nelson, and E. W. Spannhake. 1978. Pulmonary and systemic vasodilator effects of the newly discovered prostaglandin, $\mathrm{PGI}_{2}$. J. Appl. Physiol. 45: 408413.

16. Kadowitz, P. J., and A. L. Hyman. 1977. Influence of a prostaglandin endoperoxide analogue on the canine pulmonary vascular bed. Circ. Res. 40: 282-287.

17. Hyman, A. L. 1969. Effects of large increases in pulmonary blood flow on pulmonary venous pressure. J. Appl. Physiol. 27: 179-185.

18. Kadowitz, P. J., P. D. Joiner, and A. L. Hyman. 1975. Influence of sympathetic stimulation and vasoactive substances on the canine pulmonary veins. J. Clin. Invest. 56: 354-365.

19. Snedecor, C. W., and W. G. Cochran. 1967. Statistical Methods. The Iowa State University Press, Ames, Iowa. 6th edition. 91-119.

20. Fowler, N. O., and J. C. Holmes. 1965. Pulmonary arterial pressure at high pulmonary flow. J. Clin. Invest. 44: 2040-2050.

21. Needleman, P., B. Jakschik, and E. M. Johnson. 1973. Sulfhydryl requirement for relaxation of vascular smooth muscle. J. Pharmacol. Exp. Ther. 187: 324-331.

22. Needleman, P., and E. M. Johnson. 1973. Mechanism of tolerance development to organic nitrates. J. Pharmacol. Exp. Ther. 184: 709-715.

23. Gruetter, C. A., B. K. Barry, D. B. McNamara, D. Y. Gruetter, P. J. Kadowitz, and L. J. Ignarro. 1979. Relaxation of bovine coronary artery and activation of coronary arterial guanylate cyclase by nitric oxide, nitroprusside, 
and a carcinogenic nitrosoamine.J. Cyclic Nucleotide Res. 5: 211-224.

24. Gruetter, C. A., P. J. Kadowitz, and L. J. Ignarro. 1981. Methylene blue inhibits coronary arterial relaxation and guanylate cyclase activation by nitroglycerin, sodium nitrite and amy nitrite. Can. J. Physiol. Pharmacol. In press.

25. Kukovetz, W. R., S. Holzman, A. Wurm, and G. Poch. 1979. Evidence for cyclic GMP-mediated relaxant effects of nitro-compounds in coronary smooth muscle. NaunynSchmiedeberg's Arch. Pharmacol. 310: 129-138.

26. Napoli, S. A., C. A. Gruetter, L. J. Ignarro, and P. J. Kadowitz. 1980. Relaxation of bovine coronary arterial smooth muscle by cyclic GMP, cyclic AMP and analogs. J. Pharmacol. Exp. Ther. 212: 469-473.

27. Wang, S. W. S., J. E. F. Pohl, D. J. Rowlands, and E. G. Wade. 1978. Diazoxide in treatment of primary pulmonary hypertension. Br. Heart J. 40: 572-574.

28. Daoud, F. S., J. T. Reeves, and D. E. Kelly. 1978. Isoproterenol as a potential pulmonary vasodilator in primary pulmonary hypertension. Am. J. Cardiol. 42: 817-822.

29. Ruskin, J. N., and A. M. Hutter. 1979. Primary pulmonary hypertension treated with oral phentolamine. Ann. Intern. Med. 90: 772-774.
30. Rubin, L. J., and R. H. Peter. 1980. Oral hydralazine therapy for primary pulmonary hypertension. N. Engl.J. Med. 302: 69-73.

31. Grover, R. F., J. T. Reeves, and S. G. Blount. 1961. Talazoline hydrochloride (Priscoline): an effective pulmonary vasodilator. Am. Heart J. 61: 5-15.

32. Hyman, A. L., and P. J. Kadowitz. 1979. Pulmonary vasodilator activity of prostacyclin $\left(\mathrm{PGI}_{2}\right)$ in the cat. Circ. Res. 45: 404-409.

33. Hyman, A. L., B. M. Chapnick, P. J. Kadowitz, W. E. M. Lands, C. G. Crawford, J. Fried, and J. Barton. 1977. Unusual pulmonary vasodilator activity of 13,14-dehydroprostacyclin methyl ester: comparison with endoperoxides and other prostanoids. Proc. Natl. Acad. Sci. U. S. A. 74: 5711-5715.

34. Hyman, A. L., and P. J. Kadowitz. 1980. Vasodilator actions of prostaglandin 6-keto- $\mathrm{E}_{1}$ in the pulmonary vascular bed. J. Pharmacol. Exp. Ther. 213: 468-472.

35. Watkins, W. D., M. B. Peterson, R. K. Crone, D. C. Shannon, and L. Levine. 1980. Prostacyclin and prostaglandin $\mathrm{E}_{1}$ for severe idiopathic pulmonary artery hypertension. Lancet. 1: 1083. 